\title{
Wood Sanitization Protocol for Export Packaging of Pinus radiata Wood Using a Radiofrequency Heat Treatment
}

\author{
Rubén A. Ananías, a,b,* Víctor Sepúlveda-Villarroel, ${ }^{a}$ José Torres-Mella, ${ }^{a}$ \\ Linette Salvo-Sepúlveda, ${ }^{\text {a,b }}$ Maximilian Wentzel, ${ }^{\mathrm{a}}$ and Carlos Salinas-Lira ${ }^{\text {a,c }}$ \\ A treatment is proposed to sanitize wood for export packaging using radio \\ frequency equipment that is capable of treating wood. This was achieved \\ by optimizing the sanitization process and developing an equation to \\ predict the total sanitization time. Statistical analysis determined that the \\ separation of plates and the power density of the equipment significantly \\ influenced the duration of a sanitization process using radio frequency \\ heating, whereas the thickness of the material was not as influential for \\ the overall process. Furthermore, the sanitization process did not influence \\ the quality of the wood; therefore, the proposed sanitization protocol \\ provided a balance between duration and the quality of the finished radiata \\ pine packaging material.
}

Keywords: Wood sanitization process; Pinus radiata; Export packaging materials; Radio frequency heating

Contact information: a: Research Laboratory of Wood Drying and Heat Treatments, University of Bío-Bío, Av. Collao 1202, Concepción, Chile; b: Department of Wood Engineering, Faculty of Engineering, University of Bío-Bío, Av. Collao 1202, Concepción, Chile; c: Department of Mechanical Engineering, Faculty of Engineering, University of Bío-Bío, Av. Collao 1202, Concepción, Chile;

* Corresponding author: ananias@ubiobio.cl

\section{INTRODUCTION}

In December of 2018, the available forest area in Chile was over 2.3 million hectares, approximately $56 \%$ of which was Pinus radiata. Thus, Pinus radiata is the most used species in the Chilean forest and wood industry (INFOR 2020), and wood used for packaging is a prominent sub-product produced by the industry. To use wood for export packaging, it must be sanitized according to ISPM 15 (2019). For $P$. radiata, the main phytosanitary risks are quarantine pests, such as the pine nematode Bursaphelenchus xylophilus (Haack et al. 2011), which has been found in packaging around the world (Dwinell 1997). To sanitize them, steam heating is typically used (Ananías et al. 2021). Alternatively, specific drying cycles are used as sanitization treatments (Ananías and Venegas 2005; Ananías et al. 2013). Because of the time it takes to reach the target temperature, dielectric heating at radio frequencies (RF) has been used as an alternative to sanitize wood and eliminate Bursaphelenchus xylophilus and other nematodes (Lăzărescu et al. 2011; Uzunovic et al. 2013; Lăzărescu et al. 2015). For effective sanitization, a minimum temperature of $60{ }^{\circ} \mathrm{C}$ must be achieved and maintained for at least for $1 \mathrm{~min}$ at the center of the wood, as shown by Hoover et al. (2010). If the minimum temperature is not reached, the nematodes can survive. These temperatures were used as the basis for 
ISPM 15 (2019) and confirmed by the Food and Agriculture Organization of the United Nations (FAO) as the standard for the treatment of packaging materials made out of wood (FAO 2014).

An optimal heat sanitization process requires a good balance between duration, cost, and quality of the treated material. Heat sanitization time, using hot saturated air or steam, is generally longer than using dielectric heat (Esquivel-Reyes et al. 2018; Zhao and Wang 2018). The dielectric properties of wood also influence its resistance to RF heating (Resch 2006). During RF heating, the conversion of electrical energy into thermal energy is important, as it is linked to the loss factor, a property that is conditioned by the wood humidity, wood temperature, and the direction of the wood grain (Avramidis 2016). In wood with high moisture content (MC), the loss factor is high and varies little, which favors the RF heating process (Huang et al. 2013). When they compared the sanitization process of two species of conifers (Pinus contorta and Thuja plicata), Lăzărescu et al. (2012) showed that heating rates were not correlated to the MC of materials, as the T. plicata heated up faster than the P. contorta at the same MC. Therefore, the species used has a greater effect on dielectric properties than $\mathrm{MC}$, although is important to clarify that the changes in MC change the mass of wood that is going to be heated during the process to up to $11 \%$ (Esquivel-Reyes 2017).

Existing RF processes are primarily used for drying wood; they use intermittent cycles of heat input and fluid circulation to avoid cracks and other drying effects (Pless 1981), control the voltage to dry wood from a green state to a MC below 20\% (Paice 2013), or combine the traditional RF process with microwave technology to achieve an optimal drying of wood (Triglia 2016). Sanitization processes involving RF have largely been carried out on a laboratory scale (Lăzărescu et al. 2009; 2011; Zhao and Wang 2018). However, an industrial-scale sanitization process is currently being patented that uses RF combined with pressure to sanitize the wood and maintain the initial MC of the specimens (Janowiak and Hoover 2018). Researchers are also currently developing protocols for the sanitization of pine-based products (Zhao and Wang 2018), but there is still no protocol or process that can be used in any type of RF equipment capable of treating wood.

This study aimed to develop and optimize the process of sanitization of green wood (moisture content higher than 60\%) and propose a program protocol for export packaging with RF heat that can be used with any equipment that is capable of treating wood.

\section{EXPERIMENTAL}

\section{Materials}

Sawn wood was from Pinus radiata D. Don plantations harvested by the CMPCMaderas Spa Company (Los Ángeles, Chile). The pieces were in a green state and collected from central wood from randomly picked logs. The pieces were $50 \mathrm{~mm} \times 100 \mathrm{~mm} \times 3100$ $\mathrm{mm}, 75 \mathrm{~mm} \times 100 \mathrm{~mm} \times 3100 \mathrm{~mm}$, and $100 \mathrm{~mm} \times 100 \mathrm{~mm} \times 3100 \mathrm{~mm}$ in size.

\section{Equipment}

Radio frequency heating equipment (Saga HF-VD30SA, Shijiazhuang, Hebei, China) was used, and it had a capacity of $3 \mathrm{~m}^{3}$ of wood, a frequency of $6.78 \mathrm{MHz}$, and 20 $\mathrm{kW}$ of power (Fig. 1). 


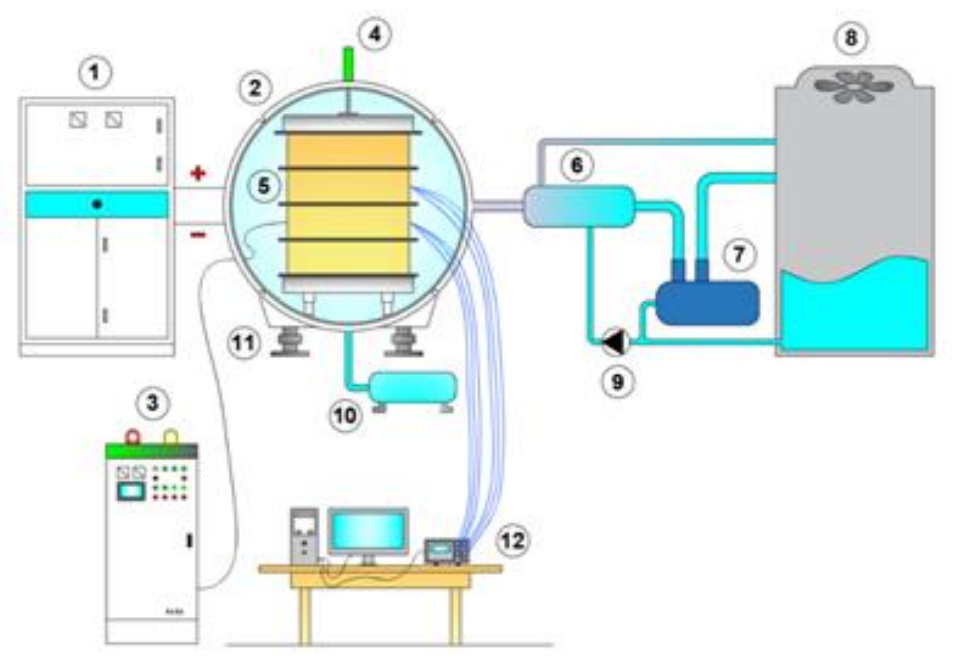

Fig. 1. Radio frequency heating equipment: (1) RF generator; (2) autoclave; (3) programmable logic controller (PLC) and fiber optic sensor; (4) hydraulic press; (5) wood; (6) cooling tank; (7) vacuum pump; (8) cooling tower; (9) water pump; (10) condensate tank; (11) load cells; (12) temperature data acquisition system

The stacked wood loads were divided into four packages separated by a distance between plates (h) of $150 \mathrm{~mm}, 200 \mathrm{~mm}$, and $300 \mathrm{~mm}$ (Fig. 2). Power densities (p) of 6, 9 $\mathrm{kW} / \mathrm{m}^{3}$, and $12 \mathrm{~kW} / \mathrm{m}^{3}$ were used.

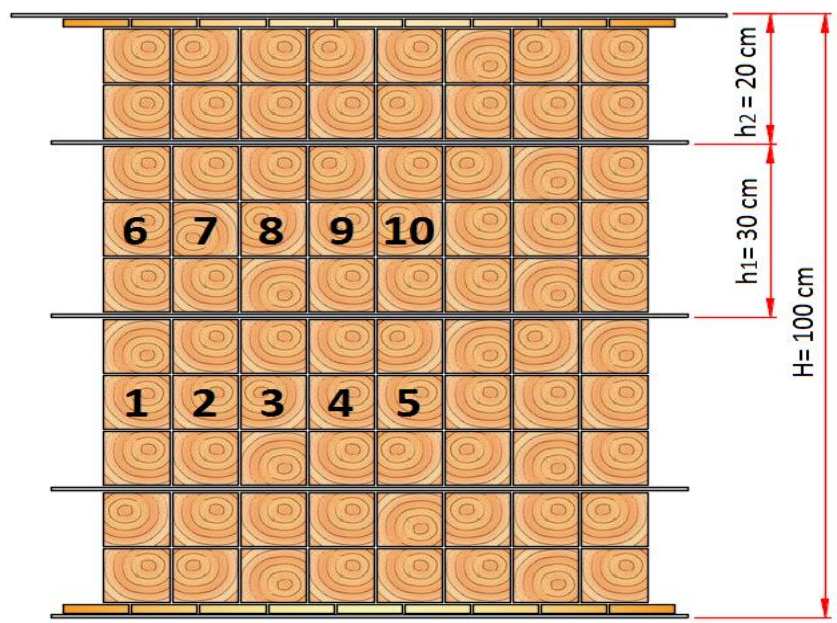

Fig. 2. Stacking of a load of wood inside the sanitization equipment; h1 and h2 are the separation between plates and $\mathrm{H}$ is the total height of the stacked wood inside the chamber. Numbers 1 to 10 indicate the position of samples that were removed to assess the quality of the processed wood.

\section{Measuring Temperature}

To measure the temperature of the wood during the process, six fiber optic sensors were installed equidistant from each other from the surface to the center of each pile. The 
temperature was monitored using Oriental Rayzer six channel data acquisition equipment (ORZ-FTM1000, Beijing Oriental RayZer Technology Ltd., Beijing, China), and the data were stored in a computer every $10 \mathrm{~s}$. The temperature of the wood surface was monitored with the fiber optic sensor associated with the programmable logic controller (PLC) of the equipment (Fig. 3). For the temperature simulation, the transformation of electromagnetic energy into sensible thermal energy (dielectric heating) was considered and added to the transportation of energy by conduction modeled by Fourier's Law, which was represented by Eq. 1,

$$
\rho c_{p} \frac{\partial T}{\partial t}=\frac{\partial}{\partial x}\left(k \frac{\partial T}{\partial x}\right)+\dot{\mathrm{q}}_{\varepsilon}(x)
$$

where $T$ is the temperature $\left({ }^{\circ} \mathrm{C}\right), t$ is the time (s), $x$ is the distance in the direction of the thickness of the specimen $(\mathrm{m}), \rho$ is the density $\left(\mathrm{kg} / \mathrm{m}^{3}\right), c_{\mathrm{p}}$ is the specific heat $\left(\mathrm{J} / \mathrm{kg} \times{ }^{\circ} \mathrm{C}\right), k$ is the thermal conductivity $\left(\mathrm{W} / \mathrm{m} \times{ }^{\circ} \mathrm{C}\right)$, and $\dot{q}$ the heat transferred by the electromagnetic field $\left(\mathrm{W} / \mathrm{m}^{3}\right)$. This was then subjected to the following initial and boundary conditions (Eq. 2),

$$
\begin{aligned}
& T=T_{0} \text { for } \mathrm{t}=0 \\
& \pm k \frac{\partial T}{\partial x}=h\left(T_{\infty}-T_{a}\right) \text { in } x= \pm a
\end{aligned}
$$

where $T_{0}$ is the initial temperature $\left({ }^{\circ} \mathrm{C}\right), T_{\infty}$ is the temperature of the heating environment $\left({ }^{\circ} \mathrm{C}\right), T_{\mathrm{a}}$ is the temperature at the wood-environment interface, and $h$ is a phenomenological coefficient of heat transfer $\left(\mathrm{W} / \mathrm{m}^{2} \times{ }^{\circ} \mathrm{C}\right)$, defined by Salinas et al. (2018) as the ratio of inner to outer ambiance heat transfer.

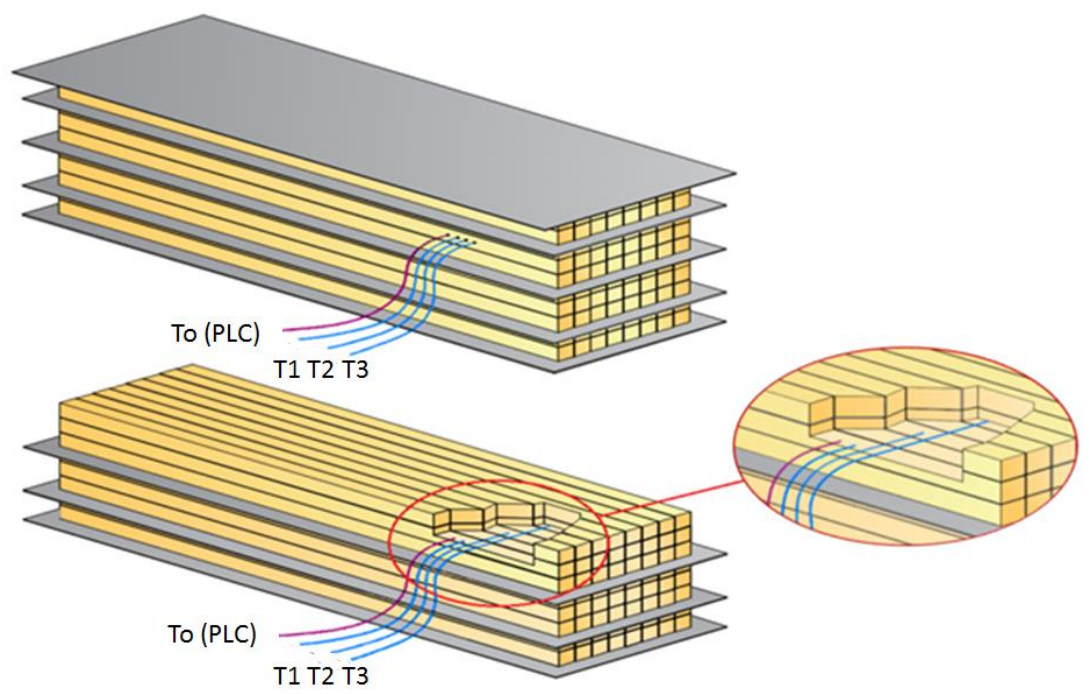

Fig. 3. Positions of the temperature sensors in the wood pile inside the RF equipment.

The total heating times were determined as $56 / 30{ }^{\circ} \mathrm{C} / \mathrm{min}$ and $60 / 1{ }^{\circ} \mathrm{C} / \mathrm{min}$ in the coldest area of the load (the surface of the wood) in accordance with ISPM 15 (2019), as those temperatures have to be maintained to their respective times to effectively sanitize the material to be able to use it for export packaging. 


\section{Wood Quality}

The quality of the wood was evaluated in 10 selected pieces of wood (Fig. 2). Warping was measured according to INN NCh993 (2018), and the quality of the treated wood was specified according to a quality index adapted from Kauman and Mittak (1966), in which twist, bow, crook, and cup were measured before and after the sanitization process (Fig. 4). In addition, the dimensional changes (width and thickness) and mass changes of the wood were controlled before and after the sanitization process.
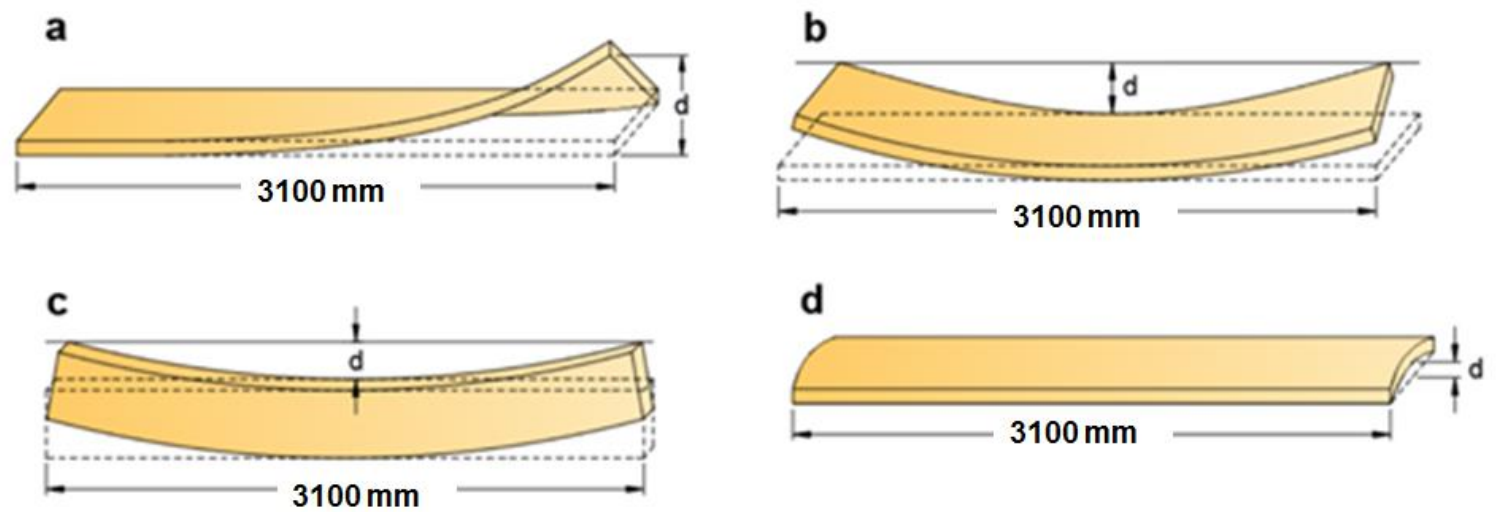

Fig. 4. Warping in wood (adapted from INN NCh993 (2018)): (a) twist; (b) bow; (c) crook; (d) cup

As per INN NCh993 (2018) Standard (Wood - Procedure and evaluation criteria for classification), warping was defined by distance $d$ in mm, as twist (Fig. 4a), bow (Fig. 4b), crook (Fig. 4c), and cup (Fig. 4d). Twist warping was defined as the movement of the edges of a board so that the four corners of either face were no longer in the same plane (distance $\mathrm{d}$ in Fig. 4a in $\mathrm{mm}$ ). Bow warping was defined as the greater deviation of the face from being a straight line along the length of the board (distance $d$ in Fig. 4b in mm). Crook warping was defined as the distance between the edge and the horizontal plane (distance $d$ in Fig $4 \mathrm{c}$ in $\mathrm{mm}$ ). Cup warping was determined by the greater distance that exists between the concave edge of the piece and the transverse plane that joins the corners or edges (distance $d$ in Fig. 4 d in $\mathrm{mm}$ ).

Table 1. Warp Intensity During RF Heating Treatments (NCh993 2018)

\begin{tabular}{|c|c|c|c|c|c|c|c|c|c|c|c|c|}
\hline \multirow[b]{3}{*}{ Warp } & \multicolumn{12}{|c|}{ Thickness (mm) } \\
\hline & \multicolumn{4}{|c|}{50} & \multicolumn{4}{|c|}{75} & \multicolumn{4}{|c|}{100} \\
\hline & $n / d$ & Mi & Mo & I & $n / d$ & Mi & Mo & 1 & $n / d$ & Mi & Mo & I \\
\hline Twist & 0 & $\begin{array}{c}1 \text { to } \\
4\end{array}$ & $\begin{array}{ll}5 & \text { to } \\
& 7\end{array}$ & $>7$ & 0 & $\begin{array}{c}1 \text { to } \\
3\end{array}$ & $\begin{array}{c}4 \text { to } \\
5\end{array}$ & $>5$ & 0 & $\begin{array}{c}1 \text { to } \\
4\end{array}$ & $\begin{array}{c}5 \text { to } \\
7\end{array}$ & $>7$ \\
\hline Bow & 0 & $\begin{array}{c}1 \text { to } \\
15\end{array}$ & 16 to 30 & $\begin{array}{c}> \\
30\end{array}$ & 0 & $\begin{array}{c}1 \text { to } \\
10\end{array}$ & $\begin{array}{c}11 \text { to } \\
20\end{array}$ & $\begin{array}{l}> \\
20\end{array}$ & 0 & $\begin{array}{c}1 \text { to } \\
8\end{array}$ & $\begin{array}{c}9 \text { to } \\
15\end{array}$ & $\begin{array}{c}> \\
15\end{array}$ \\
\hline Crook & 0 & $\begin{array}{c}1 \text { to } \\
12\end{array}$ & 13 to 25 & $\begin{array}{c}> \\
25\end{array}$ & 0 & $\begin{array}{c}1 \text { to } \\
10\end{array}$ & $\begin{array}{c}11 \text { to } \\
20\end{array}$ & $\begin{array}{l}> \\
20\end{array}$ & 0 & $\begin{array}{c}1 \text { to } \\
8\end{array}$ & $\begin{array}{c}9 \text { to } \\
15\end{array}$ & $\begin{array}{c}> \\
15 \\
\end{array}$ \\
\hline
\end{tabular}


To reduce variation in data collection, the measurements were carried out by a single person, at the same table and with the same digital measuring instrument. The defects were evaluated before and after each sanitization treatment, this was done to confirm that the changes occurred during the RF treatment. The defects were evaluated according to the intensity of each one, and the intensity of the warping was defined according to NCh993 (2018) (Table 1).

A quality index (QI) indicator was used (Kauman and Mittak 1966), as represented by Eqs. 3 and 4,

$$
\begin{aligned}
& I \mathrm{Q}=\sum D / N D \\
& D=\sum\left(n_{1}{ }^{*} 0\right)+\left(n_{2} * 0.5\right)+\left(n_{3} * 2\right)+\left(n_{4} * 2.5\right) / N
\end{aligned}
$$

where $D$ is the type of defect presented in Fig. 4, $N D$ is the number of defects, $N$ is the total number of defects, $n_{1}$ is the number of pieces without defect, $n_{2}$ is the number of pieces with mild defects, $n_{3}$ is the number of pieces with moderate defects, and $n_{4}$ is the number of pieces with intense defects. The indicator was then compared with the attribute table presented in Table 2.

Table 2. Wood Quality Attributes After the Sanitization Process (Adapted from Kauman and Mittak 1966)

\begin{tabular}{|c|c|c|}
\hline $\mathbf{Q}_{\mathbf{l}}$ & Quality & \multirow{2}{*}{ Conditions of Use } \\
\hline 0 & Excellent & \multirow{2}{*}{ Adequate } \\
\hline 0.1 to 0.5 & Very good & \multirow{2}{*}{ Poorly suited } \\
\hline 0.6 to 1 & Good & \multirow{2}{*}{ Inadequate } \\
\hline 1.1 to 1.5 & Satisfactory & \\
\hline 1.51 to 2 & Regular & \\
\hline 2.1 to 3 & Faulty & \\
\hline 3.1 to 5 & Bad & Very bad \\
\hline$>5$ & &
\end{tabular}

\section{Statistical Analysis}

A multifactorial analysis of variance (ANOVA) test was developed to analyze the factors that influenced sanitization time, and a multiple comparisons test of least significant difference (LSD) was conducted at a 95\% confidence level to determine significant differences between the levels of each factor. A Kolmogorov-Smirnov test was performed to analyze the distribution of sanitizing time between the $56 / 30{ }^{\circ} \mathrm{C} / \mathrm{min}$ and $60 / 1{ }^{\circ} \mathrm{C} / \mathrm{min}$ programs. To determine the relationship between the sanitization time and the selected factors (separation between the plates, wood thickness, and power density), multiple regression models were studied, and the quality of the models was verified through residuals, autocorrelation, and goodness of fit using the Statgraphic Centurion 16.2 (Statgraphics Technologies, Inc., The Plains, VA, USA) statistical package.

\section{RESULTS AND DISCUSSION}

Trial sanitization processes for both programs $\left(56 / 30{ }^{\circ} \mathrm{C} / \mathrm{min}\right.$ and $\left.60 / 1{ }^{\circ} \mathrm{C} / \mathrm{min}\right)$ were run, and the temporal evolution of the temperature inside the chamber is shown in Fig. 5, showing that the coldest zone was found on the surface of the wood, which is 
required to measure the temperature (ISPM 15 2019). In contrast, the center and the middle of the pile heated up quickly. These results complemented those presented by EsquivelReyes et al. (2018), who also found a similar difference between the intermediate zone and the wood surface of the pile inside the chamber. This finding confirmed the importance of the position of the measuring equipment to determine the temperature at which the sanitization process can be completed. The temporal and spatial simulation models of the temperature after Eqs. 1 and 2 are presented in Fig. 6. A practically linear heating curve was observed from the center of the pile to the surface of the wood, which corresponded to the coldest zone of the wood pile. The results were comparable to those obtained by Esquivel-Reyes et al. (2018) with similar conditions, and were consistent with the experimental results. Thus, the results showed that it was feasible to predict how the RF affects the temperature of the process inside the chamber that is going to be used for the sanitization process.

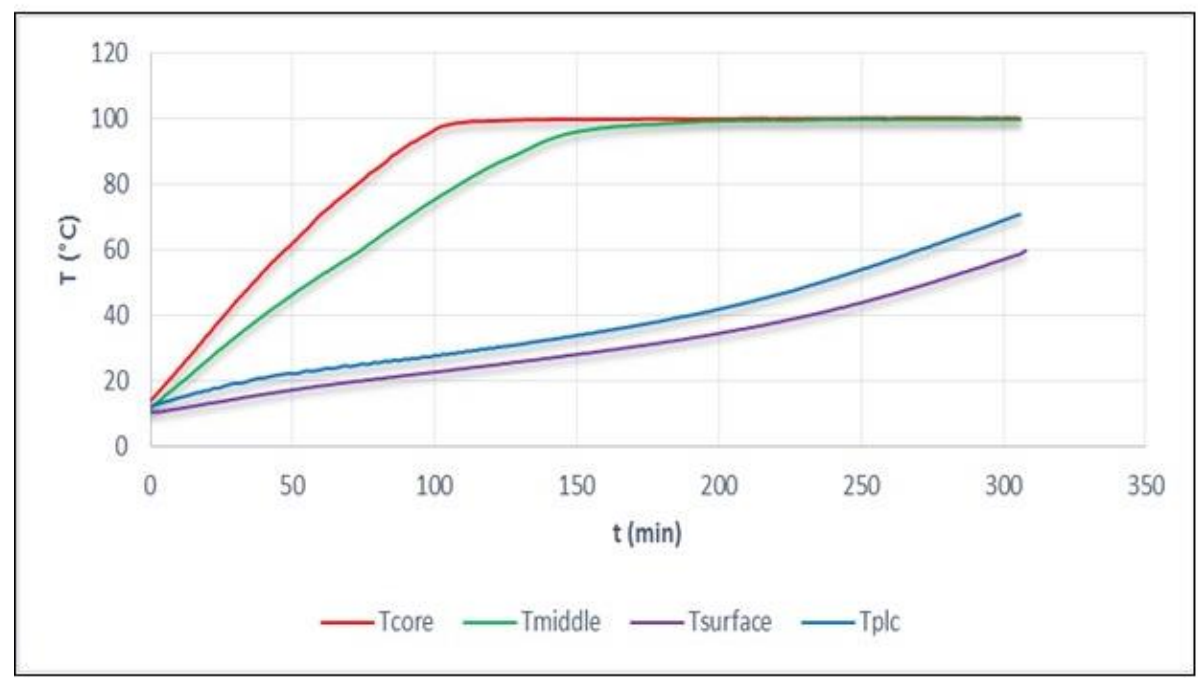

Fig. 5. Temporal evolution of temperature in stacked radiata pine wood during a RF sanitization process. Height: $150(\mathrm{~mm})$; thickness: $75(\mathrm{~mm})$; power density: $6\left(\mathrm{~kW} / \mathrm{m}^{3}\right)$

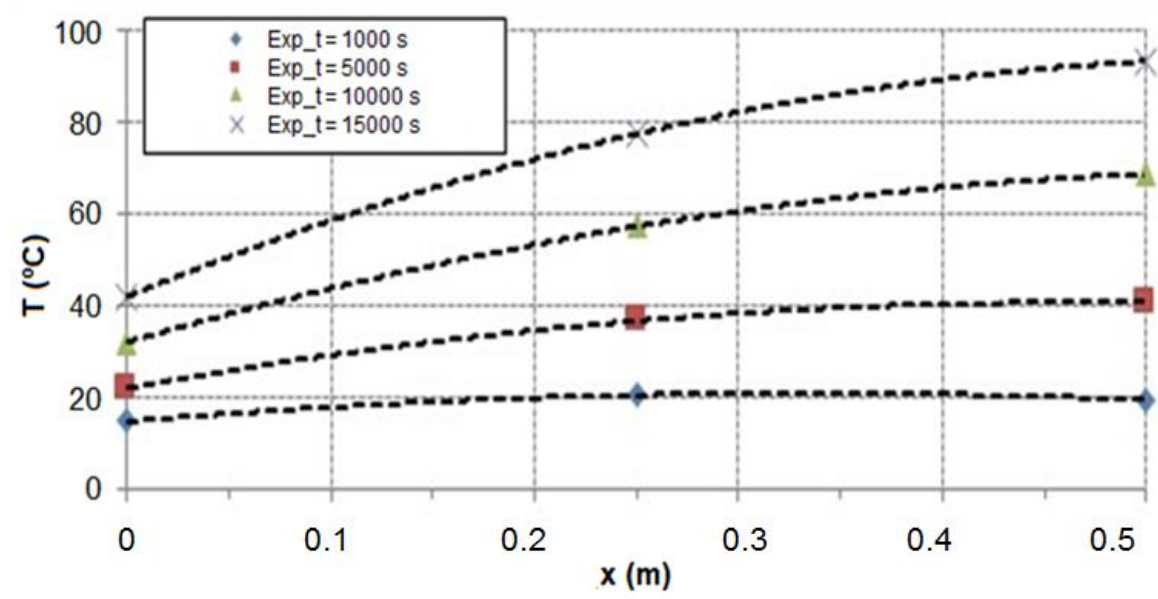

Fig. 6. Spatial and temporal variation of experimental (symbols) and simulated (segmented lines) temperatures during a RF sanitization process; Height: $200 \mathrm{~mm}$; thickness: $100 \mathrm{~mm}$; power density: $6 \mathrm{~kW} / \mathrm{m}^{3} ; \Delta \mathrm{x}=0.025 \mathrm{~m} ; \Delta \mathrm{t}=0 \mathrm{~s}$ 
The quality of the wood after the sanitization was good, and the treatment conditions were adequate for this material (Table 3). The dimensional and mass changes during the treatments did not vary significantly, as shown in Figs. 7 and 8.

Table 3. Quality Index of Sanitized Radiata Pine Wood After a Sanitization Process with RF Heating

\begin{tabular}{|c|c|c|c|c|c|c|c|c|c|}
\hline \multirow{4}{*}{$\begin{array}{l}\text { Height } \\
(\mathrm{mm})\end{array}$} & \multicolumn{9}{|c|}{ Density $\left(\mathrm{kW} / \mathrm{m}^{3}\right)$} \\
\hline & \multicolumn{3}{|c|}{6} & \multicolumn{3}{|c|}{9} & \multicolumn{3}{|c|}{12} \\
\hline & \multicolumn{3}{|c|}{ Thickness (mm) } & \multicolumn{3}{|c|}{ Thickness (mm) } & \multicolumn{3}{|c|}{ Thickness (mm) } \\
\hline & 50 & 75 & 100 & 50 & 75 & 100 & 50 & 75 & 100 \\
\hline \multirow[t]{2}{*}{150} & 0.4 & 0.7 & - & 0.3 & 0.3 & - & 0.1 & 0.2 & - \\
\hline & $(0.3)$ & $(0.3)$ & $(-)$ & $(0.04)$ & $(0.0)$ & $(-)$ & $(0.0)$ & $(0.0)$ & $(-)$ \\
\hline \multirow[t]{2}{*}{200} & 0.3 & 0.6 & 0.3 & 0.2 & 0.2 & 0.2 & 0.2 & 0.3 & 0.1 \\
\hline & $(0.2)$ & $(0.6)$ & $(0.3)$ & $(0.05)$ & $(0.04)$ & $(0.04)$ & $(0.0)$ & $(0.0)$ & $(0.1)$ \\
\hline \multirow[t]{2}{*}{300} & 0.6 & 0.5 & 0.3 & 0.1 & 0.4 & 0.2 & 0.2 & 0.3 & 0.2 \\
\hline & $(0.4)$ & $(0.3)$ & $(0.1)$ & $(0.05)$ & $(0.05)$ & $(0.1)$ & $(0.0)$ & $(0.0)$ & $(0.1)$ \\
\hline
\end{tabular}

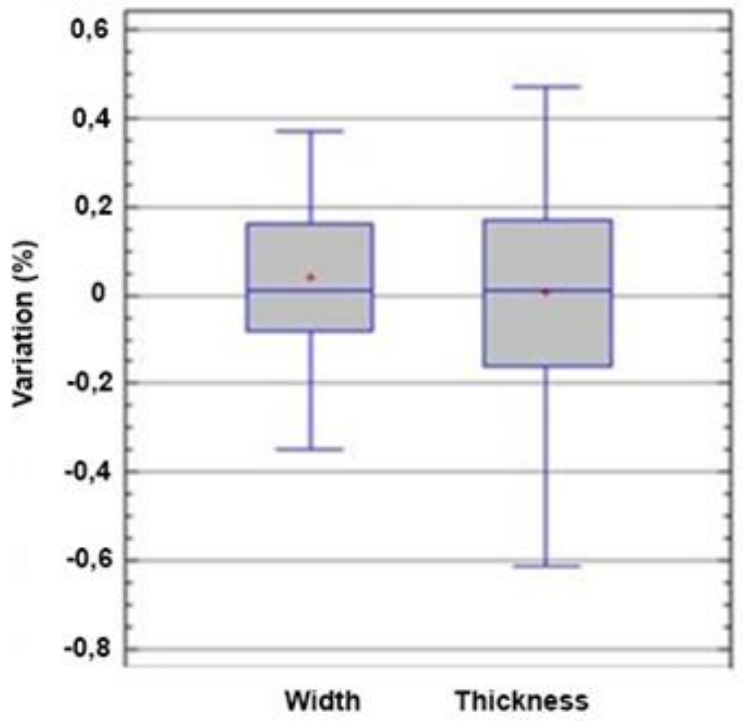

Fig. 7. Dimensional changes of radiata pine during a RF sanitization process

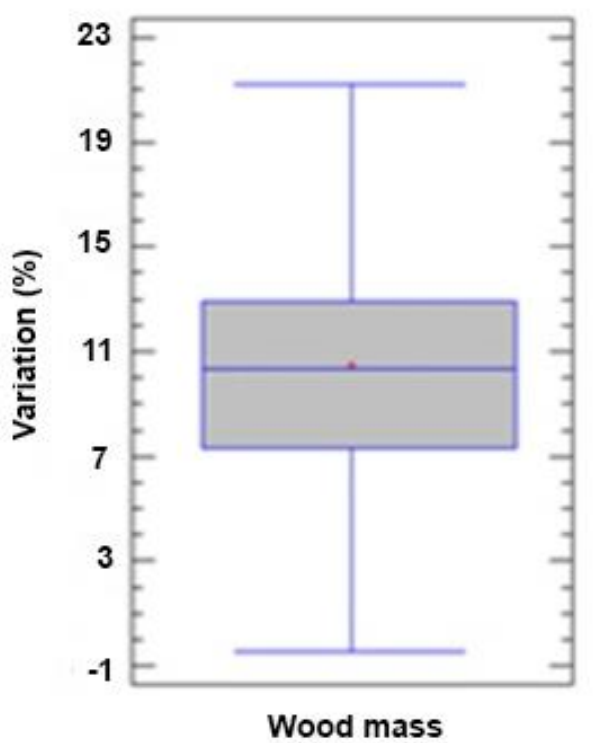

Fig. 8. Wood mass variation of radiata pine during a RF sanitization process

These results showed that the sanitization process did not affect the quality of the wood; therefore, it can be used as a complement to standard drying programs without changing the quality of the final product.

Table 4 shows the results of the sanitization time with RF heating for the 56/30 and $60 / 1\left({ }^{\circ} \mathrm{C} / \mathrm{min}\right)$ programs. The 56/30 program was finished according to ISPM 15 (2019) in an average minimum time of $152 \mathrm{~min}$ with a $150 \mathrm{~mm}$ separation between the plates, 75 $\mathrm{mm}$ of wood thickness, and $12 \mathrm{~kW} / \mathrm{m}^{3}$ of power density. However, to comply with ISPM 15 (2019) with the 60/1 program, the minimum time required was $112 \mathrm{~min}$ with $200 \mathrm{~mm}$ 
of separation between the plates, $100 \mathrm{~mm}$ of wood thickness, and $12 \mathrm{~kW} / \mathrm{m}^{3}$ of power density.

The ANOVA analysis indicated that the separation of the plates and the power density had a significant influence on the sanitization time in both programs $(p=0.0000)$. Wood thickness did not significantly influence the process ( $\mathrm{p}$-value $=0.7175$ for program $56 / 30 ;$ p-value $=0.2901$ for program 60/1). On average, the sanitization time increased as the separation of the plates increased and decreased as power density decreased. The trend with thickness was not significant in most interactions (LSD test at 95\% determined the means that were significantly different in Table 4).

Table 4. Total Sanitization Time (min) for Radiata Pine During Sanitization with RF Heating

\begin{tabular}{|c|c|c|c|c|c|c|c|c|c|c|}
\hline \multicolumn{2}{|c|}{$\begin{array}{c}\text { Separation of Plates } \\
(\mathrm{mm})\end{array}$} & \multicolumn{3}{|c|}{150} & \multicolumn{3}{|c|}{200} & \multicolumn{3}{|c|}{300} \\
\hline \multirow{2}{*}{$\begin{array}{c}\text { Power } \\
\text { Density } \\
\left(\mathrm{kW} / \mathrm{m}^{3}\right)\end{array}$} & \multirow{2}{*}{$\begin{array}{l}\text { Program } \\
\left({ }^{\circ} \mathrm{C} / \mathrm{min}\right)\end{array}$} & \multicolumn{9}{|c|}{ Thickness (mm) } \\
\hline & & 50 & 75 & 100 & 50 & 75 & 100 & 50 & 75 & 100 \\
\hline \multirow{4}{*}{6} & \multirow[t]{2}{*}{$56 / 30$} & $\begin{array}{c}261 \\
\text { abcde }\end{array}$ & $\begin{array}{c}226 \\
\text { abcde }\end{array}$ & - & $\begin{array}{l}404 \\
\text { hik }\end{array}$ & $\begin{array}{c}365 \\
\text { defgh }\end{array}$ & $\begin{array}{l}390 \\
\text { fgh }\end{array}$ & $\begin{array}{l}658 \\
\mathrm{mn}\end{array}$ & $\begin{array}{l}603 \\
j \mathrm{k} / \mathrm{m}\end{array}$ & $\begin{array}{c}500 \\
\text { abcde } \\
\text { fgh }\end{array}$ \\
\hline & & (30) & (55) & & $(188)$ & $(180)$ & $(67)$ & $(158)$ & $(90)$ & $(136)$ \\
\hline & \multirow[t]{2}{*}{$60 / 1$} & $\begin{array}{c}252 \\
\text { abcde }\end{array}$ & $\begin{array}{c}212 \\
\text { abcde }\end{array}$ & - & $\begin{array}{l}473 \\
\text { hikl }\end{array}$ & $\begin{array}{c}355 \\
\text { cdefgh }\end{array}$ & $\begin{array}{l}403 \\
\text { fgh }\end{array}$ & $\begin{array}{c}1090 \\
n\end{array}$ & $\begin{array}{l}675 \\
j l m\end{array}$ & $\begin{array}{c}347 \\
\text { abcde } \\
\text { fgh }\end{array}$ \\
\hline & & (34) & $(48)$ & & $(178)$ & $(180)$ & (37) & * & (133) & ${ }^{*}$ \\
\hline \multirow{4}{*}{9} & \multirow[t]{2}{*}{$56 / 30$} & $\begin{array}{l}168 \\
a b\end{array}$ & $\begin{array}{l}165 \\
a b\end{array}$ & - & $\begin{array}{c}275 \\
\text { abcdef }\end{array}$ & $\begin{array}{c}281 \\
\text { abcdef } \\
\text { gh }\end{array}$ & $\begin{array}{c}281 \\
\text { bcdefg } \\
h\end{array}$ & $\begin{array}{l}622 \\
i j k l\end{array}$ & $\begin{array}{c}445 \\
h\end{array}$ & $\begin{array}{l}485 \\
\text { hijkl }\end{array}$ \\
\hline & & (49) & $(28)$ & & $(50)$ & $(61)$ & $(61)$ & $(76)$ & (86) & (54) \\
\hline & \multirow[t]{2}{*}{$60 / 1$} & $\begin{array}{l}141 \\
a b\end{array}$ & $\begin{array}{l}157 \\
a b\end{array}$ & - & $\begin{array}{c}241 \\
\text { abcdefg }\end{array}$ & $\begin{array}{c}209 \\
\text { abcde }\end{array}$ & $\begin{array}{c}295 \\
\text { abcdef } \\
\text { ah }\end{array}$ & $\begin{array}{c}639 \\
j\end{array}$ & $\begin{array}{c}452 \\
\text { hij }\end{array}$ & $\begin{array}{c}450 \\
\text { defghi } \\
\text { jkl }\end{array}$ \\
\hline & & (31) & $(20)$ & & (14) & (1) & $(68)$ & $(42)$ & $(102)$ & * \\
\hline \multirow{4}{*}{12} & \multirow[t]{2}{*}{$56 / 30$} & $\begin{array}{c}164 \\
\text { abcde }\end{array}$ & $\begin{array}{l}152 \\
a b\end{array}$ & - & $\begin{array}{c}209 \\
\text { abcdefg } \\
h\end{array}$ & $\begin{array}{c}185 \\
a b c d\end{array}$ & $\begin{array}{l}178 \\
a b c\end{array}$ & $\begin{array}{c}480 \\
\text { fghijkl }\end{array}$ & $\begin{array}{c}309 \\
\text { defgh }\end{array}$ & $\begin{array}{c}436 \\
\text { ghijkl }\end{array}$ \\
\hline & & (51) & (53) & & $(60)$ & $(100)$ & (37) & (27) & (6) & (66) \\
\hline & \multirow[t]{2}{*}{$60 / 1$} & $\begin{array}{c}122 \\
a b\end{array}$ & $\begin{array}{c}144 \\
a b\end{array}$ & - & $\begin{array}{l}134 \\
a b\end{array}$ & $\begin{array}{l}171 \\
a b\end{array}$ & $\begin{array}{c}112 \\
a\end{array}$ & $\begin{array}{c}460 \\
\text { ghijkl }\end{array}$ & - & $\begin{array}{c}466 \\
\text { efghij } \\
\mathrm{kl}\end{array}$ \\
\hline & & (26) & $(83)$ & & (3) & $(80)$ & $(48)$ & (3) & & * \\
\hline
\end{tabular}

The Kolmogorov-Smirnov test (approximate p-value $=0.49984$ ) showed that the sanitization times of both programs did not significantly differ with $95 \%$ confidence (Fig. 9). The 56/30 program had an average sanitization time of $363 \mathrm{~min}$ (standard deviation of $199 \mathrm{~min}$ ), and the 60/1 program had an average time of $337 \mathrm{~min}$ (standard deviation of $215 \mathrm{~min}$ ). 


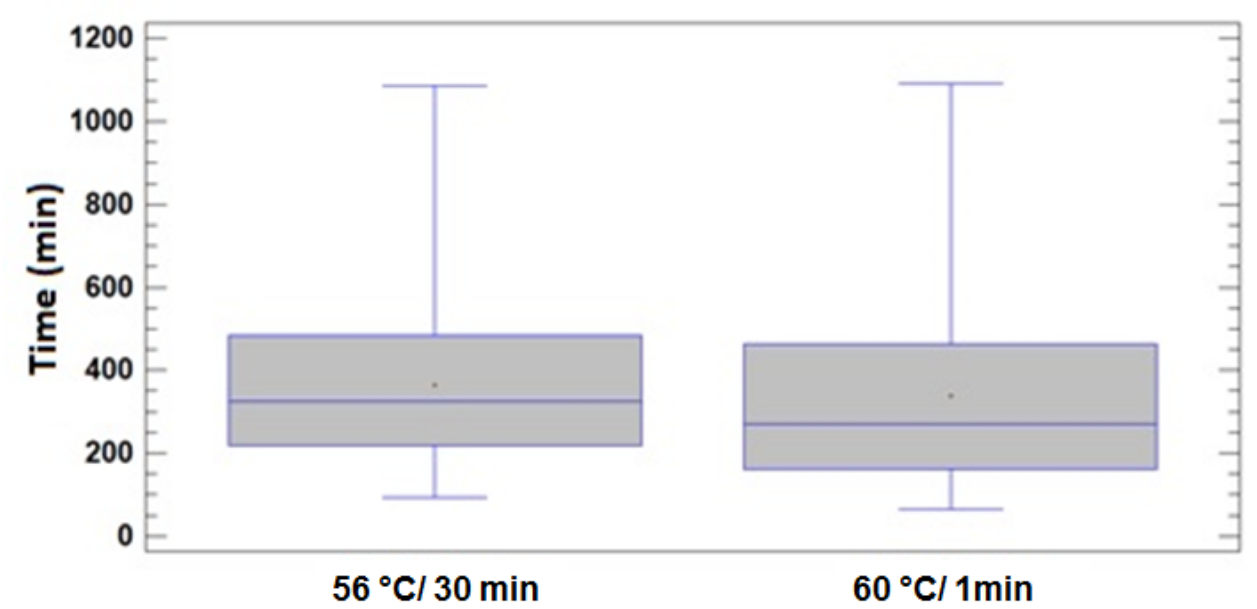

Fig. 9. Duration comparison between RF sanitization programs

The ANOVA showed a significant relationship between the separation between plates and power density with sanitizing time. The thickness of the wood specimens was not found to be significant. Nonetheless, it was incorporated into the prediction equation, considering that the adjusted model predicts the sanitizing time only in an $\mathrm{R}^{2}$ of $95 \%$, as presented in Eq. 5,

$$
t=69.1+3.5 h-52.2 p d-0.4 e
$$

where $t$ is the time in (s), $h$ is the separation of plates $(\mathrm{mm}), p d$ is the power density $\left(\mathrm{kW} / \mathrm{m}^{3}\right)$, and $e$ is the thickness of the wood specimens $(\mathrm{mm})$.

The determination coefficient $\left(\mathrm{R}^{2}\right)$ of the model with a $95 \%$ confidence level showed that the variability of the correlated time (modeled data) adjusted very strongly to the sanitization time (experimental data), in accordance with the linear regression coefficient of $\mathrm{R}=0.98$ (Table 5).

Table 5. Regression Model Analysis of Variance

\begin{tabular}{|c|c|c|c|c|}
\hline & \multicolumn{4}{|c|}{ Statistical Error } \\
\hline Parameter & Estimate & Standard & $\mathrm{T}$ & $\mathrm{p}$-value \\
\hline Constant & 69.0914 & 46.1433 & 1.49732 & 0.1451 \\
\hline Thickness & -0.370655 & 0.344003 & -1.07748 & 0.2901 \\
\hline $\begin{array}{c}\text { Separation } \\
\text { Between Plates }\end{array}$ & 3.467 & 0.148068 & 23.4149 & 0.0000 \\
\hline Power Density & -52.2319 & 3.38776 & -15.4178 & 0.0000 \\
\hline
\end{tabular}

The analysis of the residuals indicated that the adjusted model meets the assumptions of the regression: normal residuals, constant variance, and without correlation. Likewise, the Durbin-Watson statistic ( $\mathrm{DW}=2.7$ ), and the p-value of 0.9849 indicated that there was no autocorrelation of the residuals with a $95 \%$ confidence level, nor were there any studentized residuals greater than 2 .

The statistical analysis, in combination with the simulation of the temperature variation inside a RF chamber, showed that it was possible to simulate a sanitization 
process independent of the equipment used. The data obtained helped to optimize the sanitization process and was used to generate a feasible equation that was able to predict the time it took to complete the process. As for the configuration of the material to be sanitized, it can be complemented by the results obtained by Zhao and Wang (2018), who experimented with differences in width among the specimens used to carry out a program of sanitization of Pinus sylvestris wood, in which they showed that the width of the wood also influences the uniformity of the heating of the wood. Therefore, the standardization of the material to be used is important when defining a sanitation protocol process. Nonetheless, having a standardized method to calculate the time it takes based on the separation of plates, power density, and the thickness of the wood facilitates the configuration of the material to be sanitized and the calculation of the cost of the process in relation to its duration and the size of the specimens to be used.

The proposed equation for the prediction of time will help to develop a process protocol that provides a balance between the final quality of the wood and the duration of the sanitization process using any type of RF chamber. More experiments are required to extend this protocol to other species and test it on an industrial scale.

\section{CONCLUSIONS}

1. The statistical analysis showed that the variable of wood thickness was not statistically significant. However, it was incorporated to the equation used to predict the sanitization time, considering that the adjusted model predicts the sanitizing time only with an $\mathrm{R}^{2}$ of $95 \%$.

2. The simulations of the spatial and temporal variation of mean temperatures during radio frequency (RF) heating for the sanitization of radiata pine wood were satisfactorily modeled, and it was revealed that the sanitizing programs $56 / 30\left({ }^{\circ} \mathrm{C} / \mathrm{min}\right)$ and $60 / 1$ $\left({ }^{\circ} \mathrm{C} / \mathrm{min}\right)$ were similar in their heat distribution inside the chamber.

3. The sanitization process did not affect the quality of the wood in the $56 / 30{ }^{\circ} \mathrm{C} / \mathrm{min}$ or $60 / 1^{\circ} \mathrm{C} / \mathrm{min}$ sanitizing programs.

4. The obtained simulation of time equation can be used to generate a standardized sanitization process protocol that can be used for radiata pine wood for export packaging using RF equipment that is capable of treating wood.

\section{ACKNOWLEDGMENTS}

The authors are grateful for the funding of Anid to the research project FondefIdea IT18I0038. 


\section{REFERENCES CITED}

Ananías, R. A., Villarroel, V. S., and Sepúlveda, S. L. (2021). "Tratamientos de esterilización mediante vapor de la madera aserrada de pino radiata [Steam sterilization time of stacked radiata pine packaging material]," Maderas. Ciencia y Tecnología 23(17), 1-14. DOI: 10.4067/s0718-221x2021000100417

Ananías, R. A., and Venegas, R. (2005). "Secado industrial del pino radiata: Tiempo de esterilización con calor y evolución temporal de la temperatura [Industrial drying of radiata pine: Heat sterilization time and wood temperature evolution time]," Maderas. Ciencia y Tecnología 7(3), 179-188. DOI: 10.4067/S0718-221X2005000300003

Ananías, R. A., Venegas, R., Salvo, L., and Elustondo, D. (2013). "Kiln schedule certification for industrial drying of radiata pine," Wood and Fiber Science 45(1), 98104.

Avramidis, S. (2016). "Dielectric properties of four softwood species at low-level radio frequencies for optimized heating and drying," Drying Technology 34(7), 753-760. DOI: $10.1080 / 07373937.2015 .1072719$

Dwinell, L. D. (1997). “The pinewood nematode: Regulation and mitigation,” Annual Review of Phytopathology 35(1), 153-166. DOI: 10.1146/annurev.phyto.35.1.153

Esquivel-Reyes, H. (2017). "Análisis de la calidad de la madera de pino radiata sometida a tratamiento térmico de esterilización con calor por radiofrecuencia. [Wood quality analysis of radio frequency heating for sterilization of wood packaging material of radiata pine]". In Spanish. M. Sc. Thesis, Wood Science and Technology, Department of Wood Engineering, University of Bío-Bío, Concepción, Chile. p-p 1-50.

Esquivel-Reyes, H., Sepúlveda-Villarroel, V., Torres-Mella, J., Salvo-Sepúlveda, L., Salinas-Lira, C., and Ananías, R. A. (2018). "Calentamiento por radiofrecuencia para esterilizar Pinus radiata como material para embalajes. Parte 1: Tiempo total de tratamiento [Radio frequency heating for sterilization of wood packaging material of radiata pine. Part 1: Total treatment time]," Maderas. Ciencia y Tecnología 20(4), 543-552. DOI: 10.4067/S0718-221X2018005004201

Food and Agriculture Organization (FAO) (2014). "Dielectric heating as a treatment for wood packaging material," in: Proceedings of the International Plant Protection Convention, Rome, Italy, pp. 1-4.

Haack, R. A., Uzunovic, A., Hoover, K., and Cook, J. A. (2011). "Seeking alternatives to probit 9 when developing treatments for wood packaging materials under ISPM No. 15," OEPP/EPPO Bulletin 41(1), 39-45. DOI: 10.1111/j.1365-2338.2010.02432.x

Hoover, K., Uzunovic, A., Gething, B., Dale, A., Leung, K., Ostiguy, N., and Janowiak, J. J. (2010). "Lethal temperature for pinewood nematode, Bursaphelenchus xylophilus, in infested wood using microwave energy," Journal of Nematology 42(2), 101-110.

Huang, R., Wu, Y., Zhao, Y., Lu, J., Jiang, J., and Chen, Z. (2013). "Factors affecting the temperature increasing rate in wood during radio-frequency heating," Drying Technology 31(2), 246-252. DOI: 10.1080/07373937.2012.728269

INFOR (2020). Statistical Bulletin $N^{\circ} 174$ - Chilean Statistical Yearbook of Forestry 2020, Instituto Forestal de Chile [Forestry Institute of Chile], Santiago, Chile.

INN NCh993 (2018). "Madera - Procedimiento y criterios de evaluación para clasificación [Wood - Procedure and evaluation criteria for classification]," Instituto 
Nacional de Normalización [Chilean National Inst. Standardization], Santiago, Chile. ISPM 15 (2019). "Regulation of wood packaging material in international trade (Revision ISPM 15, Annex 1). Approved treatments that are associated with wood packaging," International Plant Protection Convention, Rome, Italy.

Janowiak, J. J., and Hoover, K. (2018). "Radio frequency treatment to phytosanitize wood packaging materials used in international shipping," U.S. Patent No. 2018/0177904 A1.

Kauman, W. G., and Mittak, K. (1966). Informe Técnico 25: Ensayos de Secado en Coigue (Nothofagus dombeyi) [Drying Tests in Coigue (Nothofagus dombeyi)] (Technical Report No. 25), Instituto Forestal de Chile [Forestry Institute of Chile], Santiago, Chile.

Lăzărescu, C., Bedelean, B., and Avramidis, S. (2012). "Heating characteristics of softwoods in a high frequency field," Pro Ligno 8(4), 18-26.

Lăzărescu, C., Breuil, C., and Avramidis, S. (2015). "Phytosanitation of mountain pine beetle infected lodgepole pine using dielectric fields at radio frequencies," Maderas. Ciencia y Tecnología 17(2), 221-228. DOI: 10.4067/S0718-221X2015005000021

Lăzărescu, C., Dale, A., Uzunovic, A., Breuil, C., and Avramidis, S. (2011). "Radio frequency heating pasteurization of pine wood nematode (Bursaphelenchus xylophilus) infected wood," European Journal of Wood and Wood Products 69(4), 573-578. DOI: 10.1007/s00107-010-0515-X

Lăzărescu, C., Plattner, A., Hart, F., Breuil, C. and Avramidis, S. (2009). "Pasteurization of hemlock by radio frequency heating: A preliminary study," Forest Products Journal 59(4), 79-83.

Paice, C. R. (2013). “Timber treatment using radio frequency energy," U.S. Patent No. 2010/O236.

Pless, J. H. (1981). "Method and apparatus for radio frequency drying of lumber," U.S. Patent No. 4258240.

Resch, H. (2006). "High-frequency electric current for drying of wood-historical perspectives," Maderas. Ciencia y Tecnología 8(2), 67-82. DOI: 10.4067/S0718221X2006000200001

Salinas, C., Ananias, R. A., and Vasco, D. A. (2018). "Modelling of radio-frequency heating of piles of Pinus radiata wood," BioResources 13(1), 945-953. DOI: 10.15376/biores.15.1.945-953

Triglia, J. P. (2016). "System and method of removing moisture from fibrous or porous materials using microwave radiation and RF energy," U.S. Pat. No. 016/0258680 A1.

Uzunovic, A., Gething, B., Coelho, A., Dale, A., Janowiak, J. J., Mack, R., and Hoover, K. (2013). "Lethal temperature for pinewood nematode, Bursaphelenchus xylophilus, in infested wood using radio frequency (RF) energy," Journal of Wood Science 59(2), 160-170. DOI: 10.1007/s10086-012-1306-2

Zhao, L., and Wang, S. (2018). "Developing treatment protocols for disinfesting pine wood product using radio frequency energy," European Journal of Wood and Wood Products 76(1), 191-200. DOI: 10.1007/s00107-017-1189-4

Article submitted: March 16, 2021; Peer review completed: May 16, 2021; Revised version received and accepted: May 27, 2021; Published: June 4, 2021.

DOI: $10.15376 /$ biores.16.3.5248-5260 